Article

\title{
Porous Organic Polymers Derived from Ferrocene and Tetrahedral Silicon-Centered Monomers for Carbon Dioxide Sorption
}

\author{
Xingya Zhao ${ }^{1,2,3}$, Yipeng Qi ${ }^{1}$, Jianquan $\mathrm{Li}^{1}$ and Qingyu Ma ${ }^{1, *(\mathbb{D})}$ \\ 1 School of Materials Science and Engineering, University of Jinan, Jinan 250022, China; \\ zhaoxingyaya@gmail.com (X.Z.); qiyipeng@hnksac.com (Y.Q.); mse_lijq@ujn.edu.cn (J.L.) \\ 2 College of Chemistry, Chemical Engineering and Materials Science, Shandong Normal University, \\ Jinan 250014, China \\ 3 Department of Chemistry, University of Waterloo, Waterloo, ON N2L 3G1, Canada \\ * Correspondence: mse_maqy@ujn.edu.cn; Tel.: +86-531-89736751
}

check for updates

Citation: Zhao, X.; Qi, Y.; Li, J.; Ma, Q Porous Organic Polymers Derived from Ferrocene and Tetrahedral Silicon-Centered Monomers for Carbon Dioxide Sorption. Polymers 2022, 14, 370. https://doi.org/ $10.3390 /$ polym 14030370

Academic Editor: Carlos

A. García-González

Received: 15 December 2021

Accepted: 13 January 2022

Published: 18 January 2022

Publisher's Note: MDPI stays neutral with regard to jurisdictional claims in published maps and institutional affiliations.

Copyright: (C) 2022 by the authors. Licensee MDPI, Basel, Switzerland. This article is an open access article distributed under the terms and conditions of the Creative Commons Attribution (CC BY) license (https:// creativecommons.org/licenses/by/ $4.0 /$ )

\begin{abstract}
Herein, we present two novel ferrocene-containing porous organic polymers, FPOP-1 and FPOP-2, by the Heck reactions of 1,1'-divinylferrocene with two tetrahedral silicon-centered units, i.e., tetrakis(4-bromophenyl)silane and tetrakis(4'-bromo-[1,1'-biphenyl]-4-yl)silane. The resulting materials possess high thermal stability and moderate porosity with the Brunauer-Emmer-Teller (BET) surface areas of $499 \mathrm{~m}^{2} \mathrm{~g}^{-1}$ (FPOP-1) and $354 \mathrm{~m}^{2} \mathrm{~g}^{-1}$ (FPOP-2) and total pore volumes of $0.43 \mathrm{~cm}^{3} \mathrm{~g}^{-1}$ (FPOP-1) and $0.49 \mathrm{~cm}^{3} \mathrm{~g}^{-1}$ (FPOP-2). The porosity is comparable to previously reported ferrocene-containing porous polymers. These materials possess comparable $\mathrm{CO}_{2}$ capacities of $1.16 \mathrm{mmol} \mathrm{g}^{-1}(5.10 \mathrm{wt} \%)$ at $273 \mathrm{~K}$ and $1.0 \mathrm{bar}$, and $0.54 \mathrm{mmol} \mathrm{g}^{-1}(2.38 \mathrm{wt} \%)$ at $298 \mathrm{~K}$ and $1.0 \mathrm{bar}$ (FPOP-1). The found capacities are comparable to, or higher than many porous polymers having similar or higher surface areas. They have high isosteric heats of up to $32.9 \mathrm{~kJ} \mathrm{~mol}^{-1}$, proving that the affinity between the polymer network and $\mathrm{CO}_{2}$ is high, which can be explained by the presence of ferrocene units in the porous networks. These results indicate that these materials can be promisingly utilized as candidates for the storage or capture of $\mathrm{CO}_{2}$. More ferrocene-containing porous polymers can be designed and synthesized by combining ferrocene units with various aromatic monomers under this strategy and their applications could be explored.
\end{abstract}

Keywords: porous organic polymers; ferrocene; silicon-centered monomers; carbon dioxide sorption; gas storage

\section{Introduction}

Porous organic polymers (POPs) are a specific class of covalently bonded functional materials containing permanent porosity and constructed from organic monomers through various synthetic methodologies. By virtue of their diversified functionality (e.g., porosity, fluorescence, ionic charges), POP materials have found extensively potential applications in gas separation, gas storage, capture of pollutants, optoelectronics, energy storage, catalysis, sensing, nanoreactors, and medical applications [1-6]. Among various POP materials, the metal atoms containing POPs have gained particular interest as the incorporation of metal sites into the porous networks could impart the resultant materials new functions (e.g., catalytic activity and fluorescence), and thus extend/enhance their application performance (e.g., enhanced $\mathrm{CO}_{2}$ adsorption) [7-16]. For example, Son et al., reported a mesoionic carbene-Rh species containing microporous organic polymer exhibiting high catalytic activity in the stereoselective polymerization of arylacetylenes by the functionalization of azide-alkyne click-based microporous polymer [9]. The vanadium-docked covalent organic frameworks have served as efficient heterogeneous catalysts for Mannich-type reactions [17]. By doping alkali-metal into POP networks, the $\mathrm{CO}_{2}$ and $\mathrm{H}_{2}$ uptakes could 
be efficiently improved due to the enhanced isosteric heat of gas adsorption values [8]. At present, most of them were prepared by post-synthetic modification, i.e., by post metalation treating with pre-synthesized POPs containing coordinated atoms (e.g., N, S) or functional groups [8,18-22]. However, the successful achievement of these materials requires at least two steps. In addition, the modification efficiency of metal sites or nanoparticles on the frameworks may be not very high due to the heterogeneous characteristic, and the metal sites may also aggregate in the networks. It could be expected that the direct synthetic strategy based on predesigned monomers containing metal sites is more convenient by selecting various polymerization reactions, including the Sonogashira-Hagihara reaction, Suzuki reaction, Yamamoto reaction, and Friedel-Crafts reaction, etc. [1,2,23]. Furthermore, this strategy can lead to regular and homogeneous dispersion of metal sites in the networks, thus allowing for enhanced interactions between the frameworks and guest analytes (e.g., gas) and higher performance [24].

Ferrocene as a typical metallocene has been widely introduced into polymers to construct novel functional materials and extend their applications, such as magnetism, sensors, electrocatalysis, and medicine, thanks to its unique sandwich structure with special functionality [10,25-27]. Recently, ferrocene was also incorporated into POP networks and endow them new applications or enhanced performance. For example, Liu et al., reported ferrocene-based conjugated microporous polymers with intrinsic magnetism and the saturation magnetization of the materials can be adjusted by combining ferrocene with monomers with different conjugated degree [28]. By taking advantage of abundant ferrocene with high electron density and strong interaction with iodine molecules, a ferrocene-containing porous network FcTz-POP exhibited a significantly higher iodine vapor capacity than a ferrocene-free POP [29]. FcTz-POP can also served as a photocatalyst for methylene blue degradation under visible light irradiation at neutral $\mathrm{pH}$ [30]. By virtue of the strong interaction between the iron sites and gas molecules, Fu et al., constructed ferrocene-functionalized microporous aromatic polymers with a moderate porosity (BET surface area, $875 \mathrm{~m}^{2} \mathrm{~g}^{-1}$ ) and good gas sorption performance by the Friedel-Crafts reaction of ferrocene and s-triazine monomers [24]. Liu et al., reported ferrocene-based conjugated microporous polymers exhibiting good gas storage capacity and excellent methyl violet adsorption by the Yamamoto reactions of 1,10-dibromoferrocene and 5,10,15,20tetrakis(4-bromophenyl)porphyrin or tetra( $p$-bromophenyl)methane [31]. Although some ferrocene-based POPs have been reported, compared to the abundant porous materials, the construction novel ferrocene-containing POP materials and their applications are far from fully explored [32-36]. The design and construction of novel ferrocene-based POPs is still desirable.

In the present study, we synthesized two novel ferrocene-containing porous organic polymers (FPOPs) based on 1,1'-divinylferrocene and tetrakis(4-bromophenyl)silane or tetrakis ( $4^{\prime}$-bromo-[1,1'-biphenyl]-4-yl)silane by the Heck reaction. The resulting polymers show high thermal stability and moderate porosity. Moreover, the application in $\mathrm{CO}_{2}$ adsorption was also investigated.

\section{Materials and Methods}

\subsection{Materials and Characterization}

Tetra(phosphorylation)palladium $\left(\mathrm{Pd}\left(\mathrm{PPh}_{3}\right)_{4}\right)$ and potassium carbonate $\left(\mathrm{K}_{2} \mathrm{CO}_{3}\right)$ were purchased from Energy Chemical. N,N-Dimethylformamide (DMF) was bought from Tianjin Kemiou Chemical Reagent Co., Ltd. (Tianjin, China). DMF was dehydrated with $\mathrm{CaH}_{2}$ at $80^{\circ} \mathrm{C}$ for $12 \mathrm{~h}$, distilled under vacuum, and stored with $4 \AA$ molecule sieves prior to use. 1,1'-Divinylferrocene, tetrakis(4-bromophenyl)silane, and tetrakis(4-bromobiphenyl)silane were prepared based on the methods in previous reports [37-39].

\subsection{Characterization}

Fourier-transform infrared (FT-IR) spectra were recorded on a Bruker Tensor 27 spectrophotometer (Bruker, Ettlingen, Germany). The solid-state ${ }^{13} \mathrm{C}$ cross-polarization/magic- 
angle-spinning (CP/MAS) NMR and ${ }^{29}$ Si MAS NMR spectra were measured by a Bruker AVANCE-500 NMR Spectrometer, while the operating magnetic field strength is $9.4 \mathrm{~T}$. The field-emission scanning electron microscopy (FE-SEM) images was observed by a FEI QUANTA FEG250 Spectrometer (FEI, Hillsboro, OR, USA). Before observation, the samples were prepared by dropping the suspensions in ethanol on a copper grid and following air drying. The thermogravimetric analysis (TGA) was determined by a MettlerToledo SDTA-854 TGA system (Greifensee, Switzerland). The samples were heated at a rate of $10{ }^{\circ} \mathrm{C} \mathrm{min}^{-1}$ in the range of room temperature to $800^{\circ} \mathrm{C}$ in an atmosphere of nitrogen.

Nitrogen sorption isotherms were measured at $77 \mathrm{~K}$ with a Micromeritics ASAP 2020 (Norcross, GA, USA) volumetric adsorption analyzer. Prior to the measurement, the samples of ca. $100 \mathrm{mg}$ were degassed in vacuum at $150{ }^{\circ} \mathrm{C}$ for $12 \mathrm{~h}$. The specific surface areas were calculated based on the nitrogen adsorption data by Brunauer-Emmett-Teller (BET) analysis in the relative pressure $\left(\mathrm{P} / \mathrm{P}_{0}\right)$ range of $0.01 \sim 0.20$, whereas the pore size distribution was evaluated on the basis of nonlocal density functional theory (NL-DFT). The total pore volumes were calculated at $\mathrm{P} / \mathrm{P}_{0}=0.99$, whereas the micropore surface area and micropore volume were calculated using the $t$-plot method. The carbon dioxide $\left(\mathrm{CO}_{2}\right)$ adsorption isotherms were measured on a Micrometrics ASAP 2020 volumetric adsorption analyzer at $298 \mathrm{~K}$ and $273 \mathrm{~K}$. Before the measurements, the samples were degassed in vacuum at $150{ }^{\circ} \mathrm{C}$ for at $12 \mathrm{~h}$.

\subsection{Synthesis of FPOP-1}

In a three-necked bottle, $1,1^{\prime}$-divinylferrocene $(0.24 \mathrm{~g}, 1 \mathrm{mmol})$, tetrakis(4-bromophenyl) silane (0.33 g, $0.5 \mathrm{mmol}), \mathrm{K}_{2} \mathrm{CO}_{3}(0.55 \mathrm{~g}, 4 \mathrm{mmol}), \mathrm{Pd}\left(\mathrm{PPh}_{3}\right)_{4}(0.12 \mathrm{~g}, 0.10 \mathrm{mmol})$, and $20 \mathrm{~mL}$ of freshly distilled DMF were added under an atmosphere of argon. The argon was bubbled into the mixture for at least $0.5 \mathrm{~h}$ to remove oxygen in the system. Then, the mixture was heated to $120^{\circ} \mathrm{C}$ and kept for $72 \mathrm{~h}$ under argon. The resultant mixture was cooled to room temperature and filtered with a vacuum equipment. The resultant precipitate was washed with various solvents, including water, methanol, chloroform, tetrahydrofuran (THF), and acetone to remove the residuals. The obtained crude product was further purified by Soxhlet extraction with methanol and THF for $24 \mathrm{~h}$, respectively. Finally, the product, which was denoted as FPOP-1, was dried in a vacuum oven at $80^{\circ} \mathrm{C}$ for $24 \mathrm{~h}$ and appeared as a red-brown solid (213 mg, yield: 53.0\%). Elemental analysis calc. (wt \%) for $\mathrm{SiC}_{52} \mathrm{H}_{36} \mathrm{Fe}_{2}$ : C 78.2, H 4.3; found C 72.5, $\mathrm{H} 4.0$.

\subsection{Synthesis of FPOP-2}

The synthetic and post-treatment procedures of FPOP-2 were similar to those of FPOP1 except that tetrakis $\left(4^{\prime}\right.$-bromo-[1, $1^{\prime}$-biphenyl]-4-yl)silane $(0.48 \mathrm{~g}, 0.5 \mathrm{mmol})$ was used as the starting material instead of tetrakis(4-bromophenyl)silane. FPOP-2 was obtained as a red-brown powder (324 mg, yield: 50.1\%). Elemental analysis calc. (wt \%) for $\mathrm{SiC}_{76} \mathrm{H}_{48} \mathrm{Fe}_{2}$ : C 82.9, H 4.4; found C 80.7, H 4.5.

\section{Results}

\subsection{Synthesis and Characterization}

The synthetic routes of two novel ferrocene-based porous organic polymers are shown in Scheme 1. FPOP-1 and FPOP-2 were prepared by the Heck coupling reactions of $1,1^{\prime}$-divinylferrocene with two tetrahedral silanes, i.e., tetrakis(4-bromophenyl)silane and tetrakis(4'-bromo-[1,1'-biphenyl]-4-yl)silane. The reactions were conducted using $\mathrm{Pd}\left(\mathrm{PPh}_{3}\right)_{4}$ as the catalyst and $\mathrm{K}_{2} \mathrm{CO}_{3}$ as the acid absorbent in DMF at $120^{\circ} \mathrm{C}$ for $72 \mathrm{~h}$ [40]. Upon the completion of the reaction, the crude products were filtrated and washed with various solvents to remove the residuals, including unreacted monomers, residual catalysts, and other impurities in the final products. Subsequently, the products were further purified by Soxhlet extraction and dried in a vacuum at $80^{\circ} \mathrm{C}$ for $24 \mathrm{~h}$. The final materials were afforded as red-brown powders. As expected, these polymers are insoluble in common solvents such as tetrahydrofuran, water, ethanol, and DMF. 


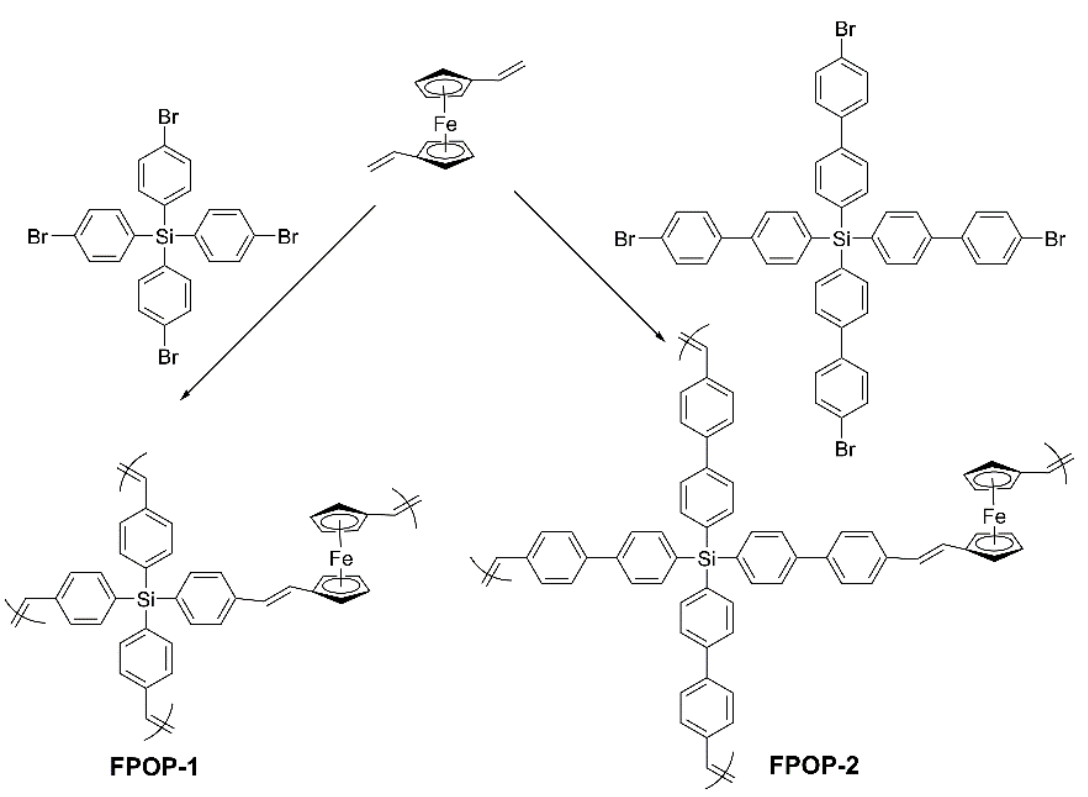

Scheme 1. Synthesis routes of FPOP-1 and FPOP-2. Reaction condition: $\mathrm{Pd}\left(\mathrm{PPh}_{3}\right)_{4}, \mathrm{DMF}$, and $\mathrm{K}_{2} \mathrm{CO}_{3}$, at $120^{\circ} \mathrm{C}$ for $72 \mathrm{~h}$. The fragments of FPOPs are shown as examples.

To confirm the structures of these polymers, they were fully characterized by FT-IR, solid-state ${ }^{13} \mathrm{C} \mathrm{CP} /$ MAS NMR, and ${ }^{29}$ Si NMR spectroscopy. FPOP-1 and FPOP-2 display similar spectra due to their similar chemical structures. For FT-IR spectra as shown in Figure 1, the multiple peaks from $1600 \mathrm{~cm}^{-1}$ to $1400 \mathrm{~cm}^{-1}$ are obviously attributed to the $\mathrm{C}=\mathrm{C}$ stretching vibrations from phenyl and cyclopentadiene rings in tetrahedral siliconcentered units and ferrocene units. The peaks ranging from $3000 \mathrm{~cm}^{-1}$ to $3100 \mathrm{~cm}^{-1}$ are apparently associated to the unsaturated $\mathrm{C}-\mathrm{H}$ stretching vibrations from phenyl and cyclopentadiene rings. In addition, two kinds of unexpected peaks were observed at ca. $3450 \mathrm{~cm}^{-1}$ and $2900-3000 \mathrm{~cm}^{-1}$. The former was attributed to $-\mathrm{OH}$ groups from water encapsulated in the samples, while the latter was aroused from saturated $\mathrm{C}-\mathrm{H}$ groups, which are from the residual solvents (e.g., THF and methanol) in the network during the Soxhlet extraction process. Although the samples have been dried under vacuum, it is very difficult to completely remove all the residual solvents, including water, THF and methanol, because some of them may be embedded in the closed pores. This finding is consistent with our previous report [41].

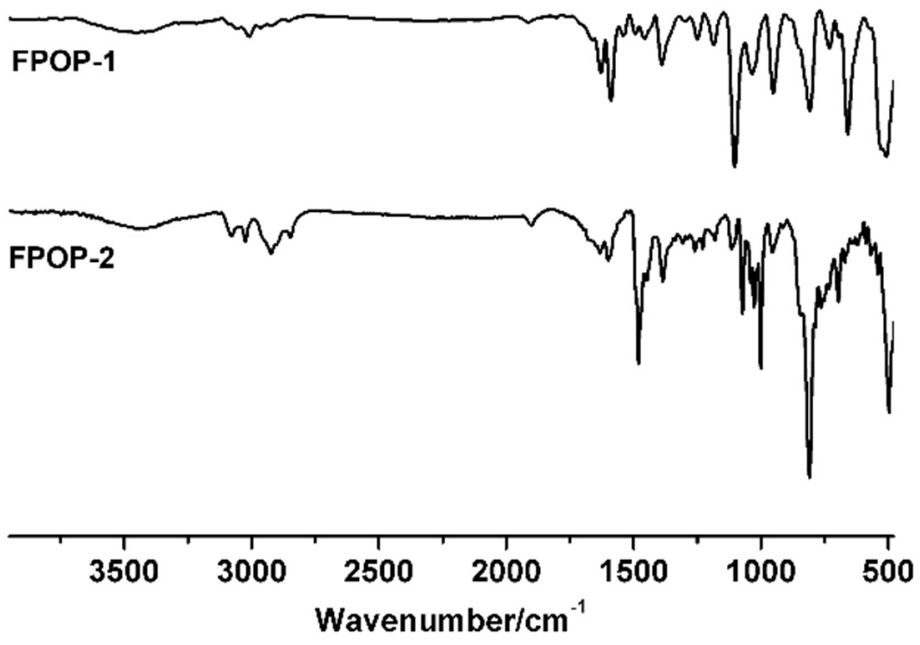

Figure 1. FT-IR of FPOP-1 and FPOP-2. 
Figure 2 shows the solid-state ${ }^{13} \mathrm{C} C P$ /MAS NMR spectra of these materials and the resonances were assigned. As expected, the peaks attributable to $s p^{2}$ carbon atoms from ethenylene, phenylene and cyclopentadiene groups in ferrocene and silicon-centered units were observed with overlapping from $120 \mathrm{ppm}$ to $150 \mathrm{ppm}$. For ${ }^{29} \mathrm{Si}$ NMR spectra, both of FPOP-1 and FPOP-2 display one peak at $-15.5 \mathrm{ppm}$ and $-15.1 \mathrm{ppm}$, respectively (Figure 3), which are unambiguously derived from the $\mathrm{Si}$ atoms from tetrahedral $\mathrm{Si}\left(p-\mathrm{C}_{6} \mathrm{H}_{4}\right)_{4}$ or $\mathrm{Si}(p-$ $\left.\mathrm{C}_{6} \mathrm{H}_{4}-\mathrm{C}_{6} \mathrm{H}_{4}\right)_{4}$ units. This finding indicates that the tetrahedral silicon units are chemically stable and no Si-C bonds have been cleaved during the reaction, in contrary to the possible $\mathrm{Si}-\mathrm{C}$ cleavage under base conditions (e.g., triethylamine or $\mathrm{K}_{2} \mathrm{CO}_{3}$ as the acid adsorbents) reported in previous literatures [38,42]. These results are in accordance with the ${ }^{29} \mathrm{Si} \mathrm{NMR}$ results found in silicon-centered POPs [43,44].

(a)
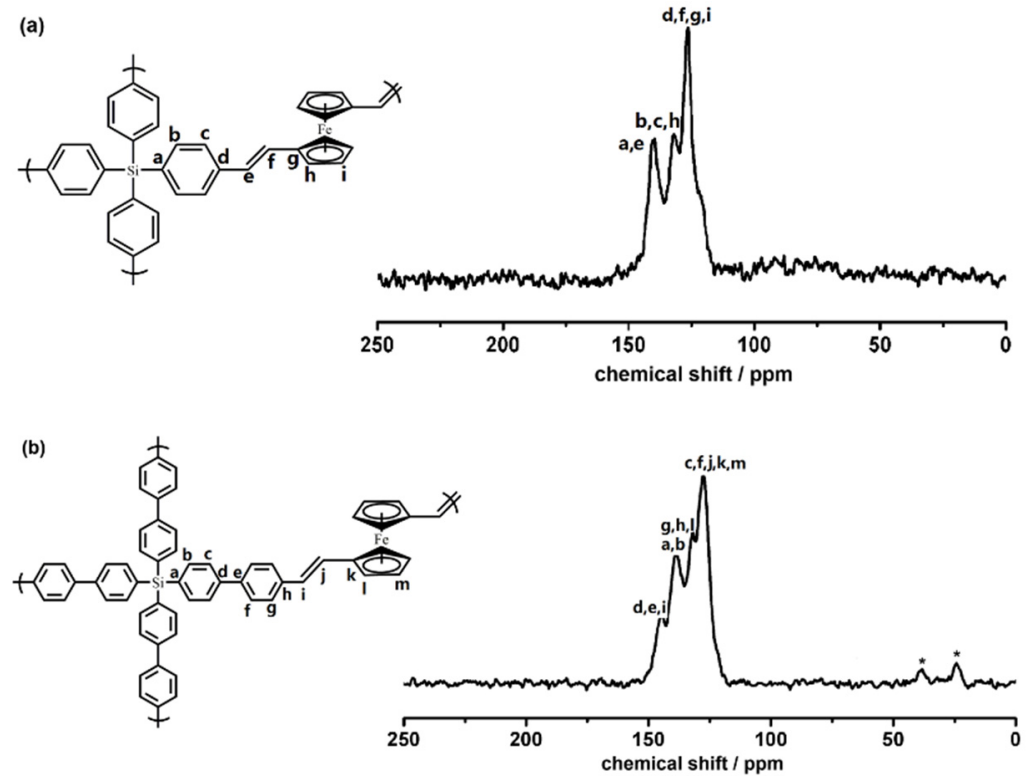

Figure 2. Solid-state ${ }^{13} \mathrm{C} \mathrm{CP} / \mathrm{MAS}$ NMR spectra of FPOP-1 (a) and FPOP-2 (b). The peak indicated by asterisk may be assigned to the carbon atom from residual methanol resulting from the Soxhlet extraction.

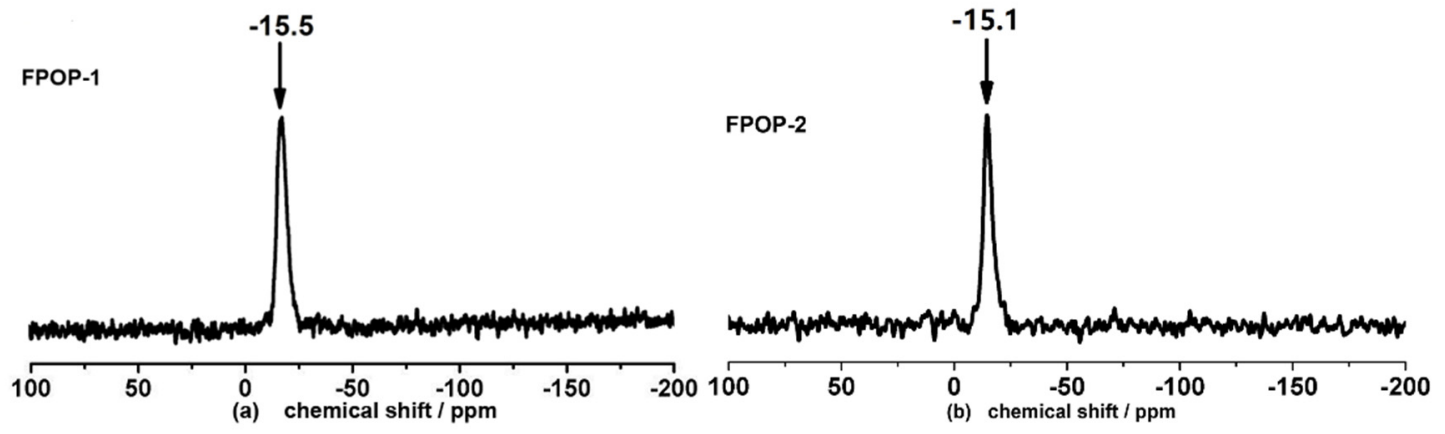

Figure 3. Solid-state ${ }^{29} \mathrm{Si} \mathrm{NMR} \mathrm{spectra} \mathrm{of} \mathrm{FPOP-1} \mathrm{(a)} \mathrm{and} \mathrm{FPOP-2} \mathrm{(b).}$

\subsection{Morphology and Thermal Stability}

Figure 4 shows the filed-emission scanning electron microscopy (FE-SEM) images of FPOP-1 and FPOP-2. As expected, these polymers are amorphous and exhibit irregular spherical or bulk particles with the scale at the micrometer sizes. 

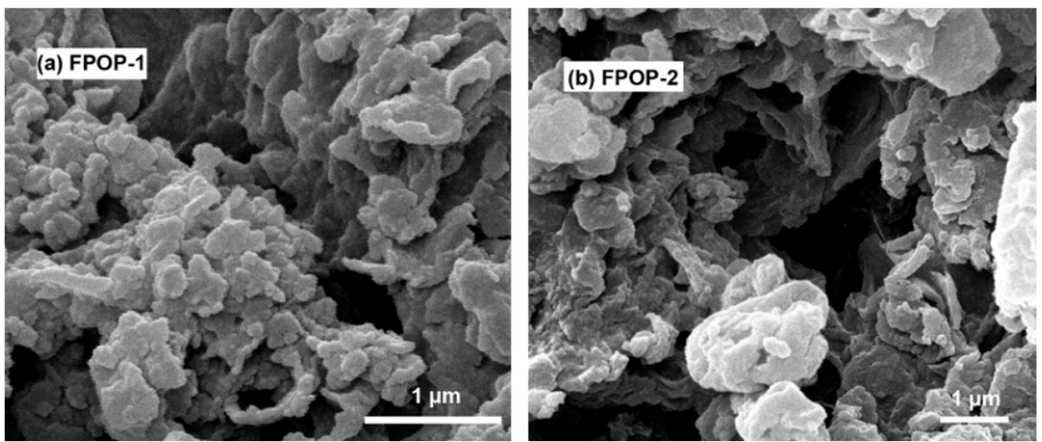

Figure 4. FE-SEM images of FPOP-1 (a) and FPOP-2 (b).

Figure 5 shows the thermogravimetric analysis (TGA) spectra of these two polymers and the analysis was conducted in an atmosphere of nitrogen at a heat rate of $10^{\circ} \mathrm{C} \mathrm{min}^{-1}$ ranging from room temperature to $800^{\circ} \mathrm{C}$. Similar to other POP materials [43,44], these polymers also have good thermal stability, while the decomposition temperatures at $5 \%$ mass loss $\left(\mathrm{T}_{\mathrm{d}, 5 \%}\right)$ were found at $405^{\circ} \mathrm{C}$ and $368{ }^{\circ} \mathrm{C}$ for FPOP-1 and FPOP-2, respectively. In addition, after the decomposition, the residual ratio of these polymers was higher than $65 \%$ at $800{ }^{\circ} \mathrm{C}$. This finding is obviously attributed to their highly cross-linking networks.

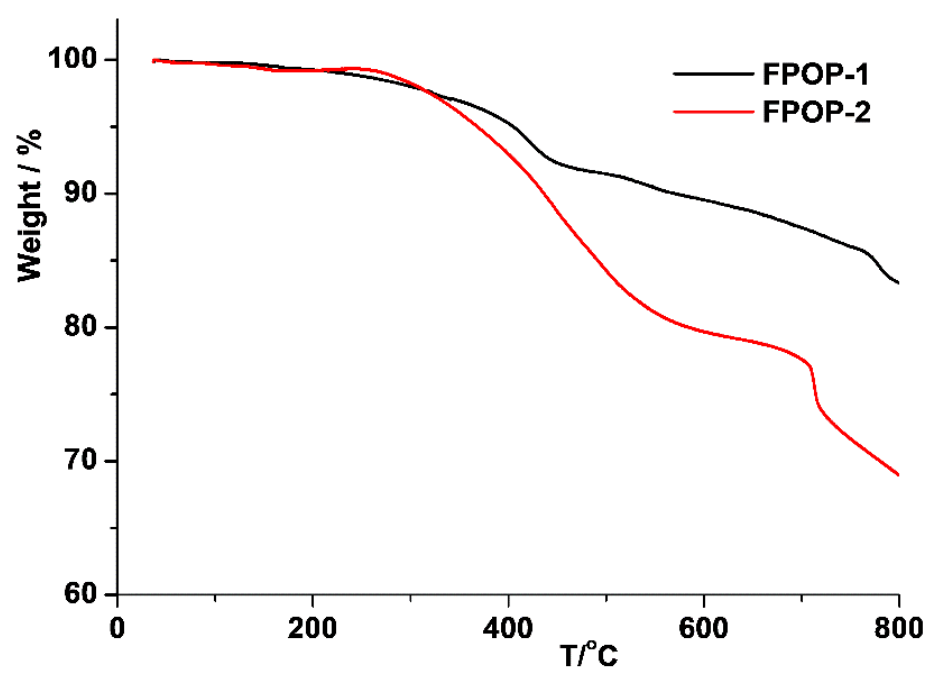

Figure 5. TGA curves of FPOP-1 and FPOP-2 in nitrogen atmosphere.

\subsection{Porous Properties}

The porous properties of these polymers were evaluated by nitrogen adsorptiondesorption isotherms at $77 \mathrm{~K}$ (Figure 6a) and the data are summarized in Table 1. The isotherms of FPOP-1 and FPOP-2 are similar. Both of them display both type I isotherm and type IV isotherm according to the IUPAC classification [45]. They give rise to a sharp capacity at relatively low pressure and a gradually increasing capacity at relatively higher pressure with hysteresis. This feature indicates that both micropores and mesopores exist within the network. On the basis of the $\mathrm{N}_{2}$ isotherm, FPOP- 1 has a moderate porosity with the Brunauer-Emmer-Teller (BET) surface area (S $\mathrm{BET}$ ) of $499 \mathrm{~m}^{2} \mathrm{~g}^{-1}$ and the total pore volume $\left(\mathrm{V}_{\text {total }}\right)$ of $0.43 \mathrm{~m}^{3} \mathrm{~g}^{-1}$. The micropore surface area $\left(\mathrm{S}_{\text {micro }}\right)$ and the micropore volume $\left(V_{\text {micro }}\right)$ were $308 \mathrm{~m}^{2} \mathrm{~g}^{-1}$ and $0.23 \mathrm{~cm}^{3} \mathrm{~g}^{-1}$, respectively, calculated using the $t$-plot method. The $\mathrm{V}_{\text {micro }} / \mathrm{V}_{\text {total }}$ ratio, which represents the contribution of microporosity in the framework, is 0.53 , thereby indicating that mesopores and micropores provide nearly same contribution to the porous network. Compared with FPOP-1, FPOP-2 shows lower porosity with $\mathrm{S}_{\mathrm{BET}}$ of $354 \mathrm{~m}^{2} \mathrm{~g}^{-1}$ and $\mathrm{V}_{\text {total }}$ of $0.49 \mathrm{~m}^{3} \mathrm{~g}^{-1}$, and lower microporosity with $\mathrm{S}_{\text {micro }}$ of $175 \mathrm{~m}^{2} \mathrm{~g}^{-1}$ and $\mathrm{V}_{\text {micro }}$ of $0.13 \mathrm{~m}^{3} \mathrm{~g}^{-1}$. As well, FPOP-2 possesses a much lower $\mathrm{V}_{\text {micro }} / \mathrm{V}_{\text {total }}$ ratio of 0.27 , thereby indicating that the mesopores mainly contribute to the 
network. The pore size distributions (PSDs) were estimated by nonlocal density functional theory (NL-DFT). As expected, the PSD results are in accordance with the shape of nitrogen isotherms. FPOP-1 displays two main peaks in the region of micropores centered at ca. $1.4 \mathrm{~nm}$ and mesopores centered at ca. $2.1 \mathrm{~nm}$ (Figure $6 \mathrm{~b}$ ). The PSD curve of FPOP-2 is similar to that of FPOP-1 except that the mesopore region is broader and centered at $2.8 \mathrm{~nm}$. These results further reveal the co-existence of micropores and mesopores in the porous networks.
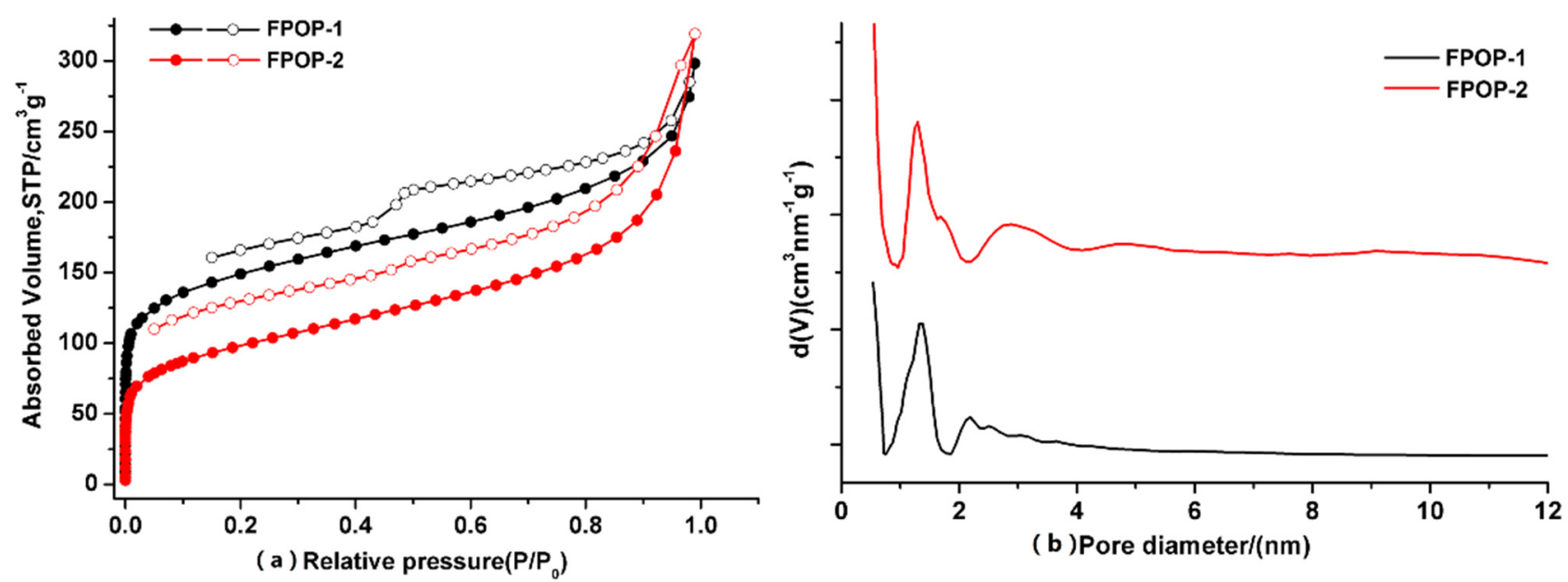

Figure 6. Nitrogen adsorption (close symbols) and desorption (open symbols) isotherms of FPOP-1 and FPOP-2 measured at $77 \mathrm{~K}$ (a); pore size distribution curves of FPOP-1 and FPOP-2 calculated by NL-DFT (b).

Table 1. Porosity data of FPOP-1 and FPOP-2.

\begin{tabular}{|c|c|c|c|c|c|c|}
\hline & $S_{\text {BET }}{ }^{(a)} / m^{2} g^{-1}$ & $\mathrm{~S}_{\text {micro }}{ }^{(b)} / \mathrm{m}^{2} \mathrm{~g}^{-1}$ & $\mathrm{~V}_{\text {total }}{ }^{(\mathrm{c})} / \mathrm{cm}^{3} \mathrm{~g}^{-1}$ & $\mathrm{~V}_{\text {micro }}{ }^{(\mathrm{d})} / \mathrm{cm}^{3} \mathrm{~g}^{-1}$ & $\mathrm{~V}_{\text {micro }} / \mathrm{V}_{\text {total }}$ & $\begin{array}{c}\mathrm{CO}_{2} \text { Uptake } \\
(\mathrm{wt} \%) \\
(\mathrm{e})\end{array}$ \\
\hline FPOP-1 & 499 & 308 & 0.43 & 0.23 & 0.53 & 5.10 \\
\hline FPOP-2 & 354 & 175 & 0.49 & 0.13 & 0.27 & 4.66 \\
\hline
\end{tabular}

(a) Surface areas calculated from $\mathrm{N}_{2}$ adsorption isotherm using the BET method; (b) microporous surface areas calculated from $\mathrm{N}_{2}$ adsorption isotherm using the $t$-plot method; (c) total pore volumes calculated at $\mathrm{P} / \mathrm{P}_{0}=0.90$; (d) microspore volumes derived using the $t$-plot method based on the Halsey thickness equation; ${ }^{(e)}$ carbon dioxide uptakes at 1.0 bar and $273 \mathrm{~K}$.

Compared to previously reported ferrocene-containing porous polymers, the present polymers exhibit comparable porosity $[28,29,46,47]$. For example, Yamamoto reactions of $1,1^{\prime}$-dibromoferrocene and 5,10,15,20-tetrakis(4-bromophenyl)porphyrin or tetra( $p$-bromoph enyl)methane resulted in two ferrocene-based conjugated microporous polymers (CMPs) with the $S_{B E T}$ of $638 \mathrm{~m}^{2} \mathrm{~g}^{-1}$ and $422 \mathrm{~m}^{2} \mathrm{~g}^{-1}$ [31]. We prepared a ferrocene-based POP with the $S_{B E T}$ of $542 \mathrm{~m}^{2} \mathrm{~g}^{-1}$ through the Sonogashira reaction of 1,1'-dibromoferrocene and tetrakis(4-ethynylphenyl)silane [48]. In addition, FPOP-1 exhibits higher porosity than FPOP-2. This finding may be due to the different structure length of these two siliconcentered monomers. It was known that longer monomer structure length could result in lower surface areas due to greater interpenetration and more efficient space filling in the network, which was induced by increased degree of conformational freedom [49]. In the present study, tetrakis(4'-bromo-[1,1'-biphenyl]-4-yl)silane has a longer structure length than tetrakis(4-bromophenyl)silane, thereby resulting in lower porosity.

\subsection{Carbon Dioxide Sorption}

One important application of the porous materials is gas sorption. Herein, carbon dioxide $\left(\mathrm{CO}_{2}\right)$ was selected as a representative gas because $\mathrm{CO}_{2}$ emission has played an important role in global warming and become a major concern for environment $[1,50]$. Moreover, the capture of $\mathrm{CO}_{2}$ is important and highly beneficial to reach net-zero emissions 
in the second half of the century [51]. Various porous materials, including zeolites, porous carbon, and metal-organic frameworks, have been applied as adsorbents for the capture or storage of $\mathrm{CO}_{2}$ in addition to other efficient techniques, such as membrane separation, chemical adsorption, and gas hydrates [52-54]. Among various porous materials, POPs are particularly promising thanks to their high porosity and facile tunability of their pore surface functionality (e.g., ferrocene units in the networks), which can play an important role in improving the interactions with $\mathrm{CO}_{2}$. Therefore, the $\mathrm{CO}_{2}$ adsorption ability of FPOP-1 and FPOP-2 was evaluated. The isotherms are shown in Figure 7 and the data are summarized in Table 1.
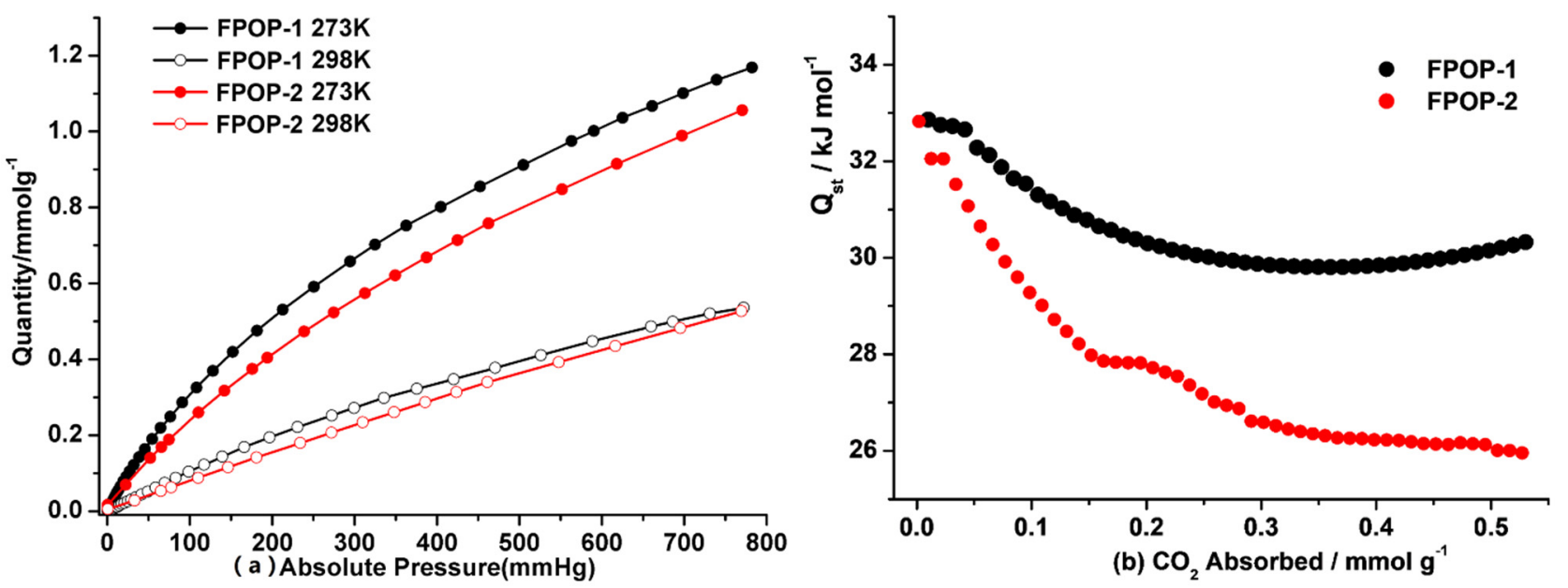

Figure 7. $\mathrm{CO}_{2}$ adsorption isotherms of FPOP-1 and FPOP-2 at 273 and $298 \mathrm{~K}(\mathbf{a})$; isosteric heat of $\mathrm{CO}_{2}$ adsorption of FPOP-1 and FPOP-2 (b).

FPOP-1 possesses moderate $\mathrm{CO}_{2}$ capacities of $1.16 \mathrm{mmol} \mathrm{g}^{-1}(5.1 \mathrm{wt} \%)$ at $273 \mathrm{~K}$ and $1.0 \mathrm{bar}$, and $0.54 \mathrm{mmol} \mathrm{g}^{-1}(2.38 \mathrm{wt} \%)$ at $298 \mathrm{~K}$ and 1.0 bar. Compared to FPOP-1, FPOP2 with a lower surface area expectedly displays lower $\mathrm{CO}_{2}$ capacity, which was found to be $1.06 \mathrm{mmol} \mathrm{g}^{-1}(4.66 \mathrm{wt} \%)$ at $273 \mathrm{~K}$ and $1.0 \mathrm{bar}$, and $0.52 \mathrm{mmol} \mathrm{g}^{-1}(2.29 \mathrm{wt} \%)$ at $298 \mathrm{~K}$ and 1.0 bar (Figure 7a). Although the values are not very high, they are comparable to some polymers having similar or much larger specific surface areas, such as triazinecontaining CMP (TCMP-5, S $\mathrm{BET}$ : $494 \mathrm{~m}^{2} \mathrm{~g}^{-1}, 1.22 \mathrm{mmol} \mathrm{g}^{-1}$ at $273 \mathrm{~K} / 1$ bar) [55], CMP-5 $\left(\mathrm{S}_{\mathrm{BET}}: 494 \mathrm{~m}^{2} \mathrm{~g}^{-1}, 1.22 \mathrm{mmol} \mathrm{g}{ }^{-1}\right.$ at $273 \mathrm{~K} / 1$ bar) [55], CMP-1-( $\left.\mathrm{NH}_{2}\right)\left(\mathrm{S}_{\mathrm{BET}}: 710 \mathrm{~m}^{2} \mathrm{~g}^{-1}\right.$, $1.56 \mathrm{mmol} \mathrm{g}^{-1}$ at $\left.273 \mathrm{~K} / 1 \mathrm{bar}\right)$, and COF-102 (S $\mathrm{SET}_{\mathrm{BET}}: 3620 \mathrm{~m}^{2} \mathrm{~g}^{-1}, 1.56 \mathrm{mmol} \mathrm{g} \mathrm{g}^{-1}$ at $273 \mathrm{~K} / 1$ bar) [56]. The interactions between the polymer framework and $\mathrm{CO}_{2}$ molecules were further evaluated by calculating the isosteric heats $\left(\mathrm{Q}_{\mathrm{st}}\right)$ while employing the ClausiusClapeyron equation from $\mathrm{CO}_{2}$ isotherms at $273 \mathrm{~K}$ and $298 \mathrm{~K}$. The $\mathrm{Q}_{\text {st }}$ values of FPOP-1 and FPOP-2 are $32.9 \mathrm{~kJ} \mathrm{~mol}^{-1}$ and $32.5 \mathrm{~kJ} \mathrm{~mol}^{-1}$ at low $\mathrm{CO}_{2}$ coverage, and gradually decrease to ca. $30 \mathrm{~kJ} \mathrm{~mol}^{-1}$ and $25 \mathrm{~kJ} \mathrm{~mol}^{-1}$ with the adsorption increasing at higher coverage, respectively (Figure $7 \mathrm{~b}$ ). These findings reveal that the polymer frameworks possess strong binding ability with $\mathrm{CO}_{2}$ because of the presence of the ferrocene unit as a withdrawing electron group, which can strongly interact with electron-rich $\mathrm{CO}_{2}$ molecules [24]. In addition, the values of $Q_{\text {st }}$ are comparable or higher than previous ferrocene-based POPs $[44,47,48]$. These results reveal that these polymers can be applied as efficient adsorbents for $\mathrm{CO}_{2}$ capture and storage.

\section{Conclusions}

Two ferrocene-containing porous organic polymers (FPOPs) were synthesized based on 1,1'-divinylferrocene and tetrahedral silicon-based monomers, i.e., tetrakis(4-bromophen yl)silane and tetrakis(4'-bromo-[1,1'-biphenyl]-4-yl)silane via the Heck reaction. The resulting materials exhibit high thermal stability and comparable porosity with the highest BET surface area of $499 \mathrm{~m}^{2} \mathrm{~g}^{-1}$ and total pore volume of $0.49 \mathrm{~cm}^{3} \mathrm{~g}^{-1}$. The porosity is com- 
parable to previous ferrocene-based POPs. For applications, these polymers display $\mathrm{CO}_{2}$ uptakes of $1.16 \mathrm{mmol} \mathrm{g}^{-1}(5.10 \mathrm{wt} \%)$ at $273 \mathrm{~K}$ and $1.0 \mathrm{bar}$, and $0.54 \mathrm{mmol} \mathrm{g}^{-1}(2.38 \mathrm{wt} \%)$ at $298 \mathrm{~K}$ and 1.0 bar (FPOP-1), which are comparable to many POP materials with similar or higher surface areas. Moreover, they both possess high isosteric heats of up to $32.9 \mathrm{~kJ} \mathrm{~mol}^{-1}$, indicating their high affinity towards $\mathrm{CO}_{2}$ due to the presence of ferrocene units in the porous networks. These results demonstrate that these materials can be promisingly used as adsorbents for the storage and capture of $\mathrm{CO}_{2}$. Further investigation will focus on the construction of ferrocene-based POPs with high surface areas by altering different aromatic monomers to react with $1,1^{\prime}$-divinylferrocene.

\begin{abstract}
Author Contributions: Conceptualization, Q.M.; methodology, X.Z., Y.Q., J.L. and Q.M.; formal analysis, X.Z., Y.Q. and J.L.; investigation, X.Z., Y.Q., J.L. and Q.M.; data curation, X.Z., Y.Q. and J.L.; writing-original draft preparation, X.Z. and Y.Q.; writing-review and editing, Q.M.; supervision, Q.M.; project administration, Q.M.; funding acquisition, J.L. and Q.M. All authors have read and agreed to the published version of the manuscript.
\end{abstract}

Funding: This research received no external funding.

Institutional Review Board Statement: Not applicable.

Informed Consent Statement: Not applicable.

Data Availability Statement: The data presented in this study are available upon request from the corresponding author.

Conflicts of Interest: The authors declare no conflict of interest.

\title{
References
}

1. Das, S.; Heasman, P.; Ben, T.; Qiu, S.L. Porous Organic Materials: Strategic Design and Structure-Function Correlation. Chem. Rev. 2017, 117, 1515-1563. [CrossRef]

2. Lee, J.-S.M.; Cooper, A.I. Advances in Conjugated Microporous Polymers. Chem. Rev. 2020, 120, 2171-2214. [CrossRef] [PubMed]

3. Taylor, D.; Dalgarno, S.J.; Xu, Z.; Vilela, F. Conjugated porous polymers: Incredibly versatile materials with far-reaching applications. Chem. Soc. Rev. 2020, 49, 3981-4042. [CrossRef] [PubMed]

4. Tian, Y.; Zhu, G. Porous Aromatic Frameworks (PAFs). Chem. Rev. 2020, 120, 8934-8986. [CrossRef] [PubMed]

5. Wang, H.; Wang, H.; Wang, Z.; Tang, L.; Zeng, G.; Xu, P.; Chen, M.; Xiong, T.; Zhou, C.; Li, X.; et al. Covalent organic framework photocatalysts: Structures and applications. Chem. Soc. Rev. 2020, 49, 4135-4165. [CrossRef] [PubMed]

6. Liu, R.; Tan, K.T.; Gong, Y.; Chen, Y.; Li, Z.; Xie, S.; He, T.; Lu, Z.; Yang, H.; Jiang, D. Covalent organic frameworks: An ideal platform for designing ordered materials and advanced applications. Chem. Soc. Rev. 2021, 50, 120-242. [CrossRef] [PubMed]

7. Sun, Q.; Dai, Z.; Liu, X.; Sheng, N.; Deng, F.; Meng, X.; Xiao, F.-S. Highly Efficient Heterogeneous Hydroformylation over Rh-Metalated Porous Organic Polymers: Synergistic Effect of High Ligand Concentration and Flexible Framework. J. Am. Chem. Soc. 2015, 137, 5204-5209. [CrossRef] [PubMed]

8. Konstas, K.; Taylor, J.W.; Thornton, A.W.; Doherty, C.M.; Lim, W.X.; Bastow, T.J.; Kennedy, D.F.; Wood, C.D.; Cox, B.J.; Hill, J.M.; et al. Lithiated Porous Aromatic Frameworks with Exceptional Gas Storage Capacity. Ang. Chem. Int. Ed. 2012, 51, 6639-6642. [CrossRef]

9. Cho, K.; Yang, H.-S.; Lee, I.-H.; Lee, S.M.; Kim, H.J.; Son, S.U. Valorization of Click-Based Microporous Organic Polymer: Generation of Mesoionic Carbene-Rh Species for the Stereoselective Synthesis of Poly(arylacetylene)s. J. Am. Chem. Soc. 2021, 143, 4100-4105. [CrossRef]

10. Abd-El-Aziz, A.S.; Shipman, P.O.; Boden, B.N.; McNeil, W.S. Synthetic methodologies and properties of organometallic and coordination macromolecules. Prog. Polym. Sci. 2010, 35, 714-836. [CrossRef]

11. Zhang, Y.; Luo, N.; Xu, J.; Liu, K.; Zhang, S.; Xu, Q.; Huang, R.; Long, Z.; Tong, M.; Chen, G. Metalated-bipyridine-based porous hybrid polymers with POSS-derived $\mathrm{Si}-\mathrm{OH}$ groups for synergistic catalytic $\mathrm{CO}_{2}$ fixation. Dalton Trans. 2020, 49, 11300-11309. [CrossRef]

12. Chen, Y.; Luo, R.; Xu, Q.; Jiang, J.; Zhou, X.; Ji, H. Metalloporphyrin Polymers with Intercalated Ionic Liquids for Synergistic $\mathrm{CO}_{2}$ Fixation via Cyclic Carbonate Production. ACS Sustain. Chem. Eng. 2018, 6, 1074-1082. [CrossRef]

13. Chen, R.F.; Shi, J.L.; Ma, Y.; Lin, G.Q.; Lang, X.J.; Wang, C. Designed Synthesis of a 2D Porphyrin-Based sp(2) Carbon-Conjugated Covalent Organic Framework for Heterogeneous Photocatalysis. Ang. Chem. Int. Ed. 2019, 58, 6430-6434. [CrossRef]

14. Chakraborty, D.; Nandi, S.; Mullangi, D.; Haldar, S.; Vinod, C.P.; Vaidhyanathan, R. Cu/Cu ${ }_{2} \mathrm{O}$ Nanoparticles Supported on a Phenol-Pyridyl COF as a Heterogeneous Catalyst for the Synthesis of Unsymmetrical Diynes via Glaser-Hay Coupling. ACS Appl. Mater. Interfaces 2019, 11, 15670-15679. [CrossRef] 
15. Diercks, C.S.; Lin, S.; Kornienko, N.; Kapustin, E.A.; Nichols, E.M.; Zhu, C.; Zhao, Y.; Chang, C.J.; Yaghi, O.M. Reticular Electronic Tuning of Porphyrin Active Sites in Covalent Organic Frameworks for Electrocatalytic Carbon Dioxide Reduction. J. Am. Chem. Soc. 2018, 140, 1116-1122. [CrossRef]

16. Ko, J.H.; Moon, J.H.; Kang, N.; Park, J.H.; Shin, H.-W.; Park, N.; Kang, S.; Lee, S.M.; Kim, H.J.; Ahn, T.K.; et al. Engineering of Sn-porphyrin networks on the silica surface: Sensing of nitrophenols in water. Chem. Commun. 2015, 51, 8781-8784. [CrossRef] [PubMed]

17. Vardhan, H.; Hou, L.X.; Yee, E.; Nafady, A.; Al-Abdrabalnabi, M.A.; Al-Enizi, A.M.; Pan, Y.X.; Yang, Z.Y.; Ma, S.Q. Vanadium Docked Covalent-Organic Frameworks: An Effective Heterogeneous Catalyst for Modified Mannich-Type Reaction. ACS Sustain. Chem. Eng. 2019, 7, 4878-4888. [CrossRef]

18. Li, A.; Lu, R.-F.; Wang, Y.; Wang, X.; Han, K.-L.; Deng, W.-Q. Lithium-Doped Conjugated Microporous Polymers for Reversible Hydrogen Storage. Ang. Chem. Int. Ed. 2010, 49, 3330-3333. [CrossRef] [PubMed]

19. Xiang, Z.; Cao, D.; Wang, W.; Yang, W.; Han, B.; Lu, J. Postsynthetic Lithium Modification of Covalent-Organic Polymers for Enhancing Hydrogen and Carbon Dioxide Storage. J. Phys. Chem. C 2012, 116, 5974-5980. [CrossRef]

20. Lin, G.; Ding, H.; Chen, R.; Peng, Z.; Wang, B.; Wang, C. 3D Porphyrin-Based Covalent Organic Frameworks. J. Am. Chem. Soc. 2017, 139, 8705-8709. [CrossRef]

21. Segura, J.L.; Royuela, S.; Ramos, M.M. Post-synthetic modification of covalent organic frameworks. Chem. Soc. Rev. 2019, 48, 3903-3945. [CrossRef] [PubMed]

22. Cai, R.; Ye, X.; Sun, Q.; He, Q.; He, Y.; Ma, S.; Shi, X. Anchoring Triazole-Gold(I) Complex into Porous Organic Polymer To Boost the Stability and Reactivity of Gold(I) Catalyst. ACS Catal. 2017, 7, 1087-1092. [CrossRef] [PubMed]

23. Yuan, Y.; Zhu, G. Porous Aromatic Frameworks as a Platform for Multifunctional Applications. ACS Cent. Sci. 2019, 5, 409-418. [CrossRef] [PubMed]

24. Fu, X.; Zhang, Y.; Gu, S.; Zhu, Y.; Yu, G.; Pan, C.; Wang, Z.; Hu, Y. Metal Microporous Aromatic Polymers with Improved Performance for Small Gas Storage. Chem. Eur. J. 2015, 21, 13357-13363. [CrossRef] [PubMed]

25. Gu, H.; Ciganda, R.; Gatard, S.; Lu, F.; Zhao, P.; Ruiz, J.; Astruc, D. On metallocene-containing macromolecules and their applications. J. Organomet. Chem. 2016, 813, 95-102. [CrossRef]

26. Zhang, H.; Xue, L.; Li, J.; Ma, Q. Hyperbranched Polycarbosiloxanes: Synthesis by Piers-Rubinsztajn Reaction and Application as Precursors to Magnetoceramics. Polymers 2020, 12, 672. [CrossRef]

27. Amer, W.A.; Wang, L.; Amin, A.M.; Ma, L.; Yu, H. Recent Progress in the Synthesis and Applications of Some Ferrocene Derivatives and Ferrocene-Based Polymers. J. Inorg. Organomet. Polym. Mater. 2010, 20, 605-615. [CrossRef]

28. Li, G.; Liu, Q.; Liao, B.; Chen, L.; Zhou, H.; Zhou, Z.; Xia, B.; Huang, J.; Liu, B. Synthesis of novel ferrocene-based conjugated microporous polymers with intrinsic magnetism. Eur. Polym. J. 2017, 93, 556-560. [CrossRef]

29. Wang, Y.; Tao, J.; Xiong, S.; Lu, P.; Tang, J.; He, J.; Javaid, M.U.; Pan, C.; Yu, G. Ferrocene-based porous organic polymers for high-affinity iodine capture. Chem. Eng. J. 2020, 380, 122420. [CrossRef]

30. Yang, Y.; Lai, Z. Ferrocene-based porous organic polymer for photodegradation of methylene blue and high iodine capture. Micropor. Mesopor. Mater. 2021, 316, 110929. [CrossRef]

31. Tan, Z.; Su, H.; Guo, Y.; Liu, H.; Liao, B.; Amin, A.M.; Liu, Q. Ferrocene-Based Conjugated Microporous Polymers Derived from Yamamoto Coupling for Gas Storage and Dye Removal. Polymers 2020, 12, 719. [CrossRef] [PubMed]

32. Chen, D.; Gu, S.; Fu, Y.; Zhu, Y.; Liu, C.; Li, G.; Yu, G.; Pan, C. Tunable porosity of nanoporous organic polymers with hierarchical pores for enhanced $\mathrm{CO}_{2}$ capture. Polym. Chem. 2016, 7, 3416-3422. [CrossRef]

33. Li, G.; Liu, Q.; Xia, B.; Huang, J.; Li, S.; Guan, Y.; Zhou, H.; Liao, B.; Zhou, Z.; Liu, B. Synthesis of stable metal-containing porous organic polymers for gas storage. Eur. Polym. J. 2017, 91, 242-247. [CrossRef]

34. Wang, Q.; Yao, L.; Hao, L.; Li, Y.; Wang, C.; Wu, Q.; Wang, Z. Ferrocene-based nanoporous organic polymer as solid-phase extraction sorbent for the extraction of chlorophenols from tap water, tea drink and peach juice samples. Food Chem. 2019, 297, 124962. [CrossRef] [PubMed]

35. Cao, X.; Wang, R.; Peng, Q.; Zhao, H.; Fan, H.; Liu, H.; Liu, Q. Effect of pore structure on the adsorption capacities to different sizes of adsorbates by ferrocene-based conjugated microporous polymers. Polymer 2021, 233, 124192. [CrossRef]

36. Hu, Q.; Fang, Y.; Yu, X.; Huang, J.; Wang, L. A ferrocene-linked metal-covalent organic polymer as a peroxidase-enzyme mimic for dual channel detection of hydrogen peroxide. Analyst 2021, 146, 487-494. [CrossRef]

37. Wang, D.; Niu, Y.; Wang, Y.; Han, J.; Feng, S. Tetrahedral silicon-centered imidazolyl derivatives: Promising candidates for OLEDs and fluorescence response of Ag (I) ion. J. Organomet. Chem. 2010, 695, 2329-2337. [CrossRef]

38. Wang, D.; Wang, L.; Xue, L.; Zhou, D.; Feng, S.; Zhao, X. Tetrahedral silicon-based luminescent molecules: Synthesis and comparison of thermal and photophysical properties by various effect factors. J. Organomet. Chem. 2013, 735, 58-64. [CrossRef]

39. Gleixner, R.M.; Joly, K.M.; Tremayne, M.; Kariuki, B.M.; Male, L.; Coe, D.M.; Cox, L.R. Reaction of 1,1'-Divinyl Ferrocene with OneElectron Oxidants: Entry into Functionalised [4] Ferrocenophanes and Observation of an Isotope-Dependent Chemoselectivity Effect. Chem. Eur. J. 2010, 16, 5769-5777. [CrossRef]

40. Sun, R.; Feng, S.; Wang, D.; Liu, H. Fluorescence-Tuned Silicone Elastomers for Multicolored Ultraviolet Light-Emitting Diodes: Realizing the Processability of Polyhedral Oligomeric Silsesquioxane-Based Hybrid Porous Polymers. Chem. Mater. 2018, 30 6370-6376. [CrossRef] 
41. Ma, Q.Y.; Yang, B.X.; Li, J.Q. Porous organic polymers derived from tetrahedral silicon-centered monomers and a stereocontorted spirobifluorene-based precursor: Synthesis, porosity and carbon dioxide sorption. RSC Adv. 2015, 5, 64163-64169. [CrossRef]

42. Sun, R.; Feng, S.; Zhou, B.; Chen, Z.; Wang, D.; Liu, H. Flexible Cyclosiloxane-Linked Fluorescent Porous Polymers for Multifunctional Chemical Sensors. ACS Macro Lett. 2020, 9, 43-48. [CrossRef]

43. Ma, Q.; Yang, B.; Li, J. Silicon-containing porous organic polymers: Preparation, tunable porosity and carbon dioxide sorption. J. Organomet. Chem. 2017, 830, 19-25. [CrossRef]

44. Sun, X.; Qi, Y.; Li, J.; Wang, W.; Ma, Q.; Liang, J. Ferrocene-linked porous organic polymers for carbon dioxide and hydrogen sorption. J. Organomet. Chem. 2018, 859, 117-123. [CrossRef]

45. Thommes, M.; Kaneko, K.; Neimark, A.V.; Olivier, J.P.; Rodriguez-Reinoso, F.; Rouquerol, J.; Sing, K.S.W. Physisorption of gases, with special reference to the evaluation of surface area and pore size distribution (IUPAC Technical Report). Pure Appl. Chem. 2015, 87, 1051-1069. [CrossRef]

46. Li, Z.; Zhang, H.; Zhu, H.; Li, L.; Liao, H. Facile synthesis of graphitic porous carbons with three-dimensional nanonetwork for high-rate supercapacitive energy storage. J. Mater. Sci. 2016, 51, 5676-5684. [CrossRef]

47. Liu, Q.; Tang, Z.; Wu, M.; Liao, B.; Zhou, H.; Ou, B.; Yu, G.; Zhou, Z.; Li, X. Novel ferrocene-based nanoporous organic polymers for clean energy application. RSC Adv. 2015, 5, 8933-8937. [CrossRef]

48. Ma, Q.; Qi, Y.; Li, J.; Wang, W.; Sun, X. A ferrocene-containing porous organic polymer linked by tetrahedral silicon-centered units for gas sorption. Appl. Organomet. Chem. 2018, 32, e3935. [CrossRef]

49. Wang, D.; Yang, W.; Feng, S.; Liu, H. Constructing hybrid porous polymers from cubic octavinylsilsequioxane and planar halogenated benzene. Polym. Chem. 2014, 5, 3634-3642. [CrossRef]

50. Xu, Y.; Jin, S.; Xu, H.; Nagai, A.; Jiang, D. Conjugated microporous polymers: Design, synthesis and application. Chem. Soc. Rev. 2013, 42, 8012-8031. [CrossRef]

51. Hassanpouryouzband, A.; Joonaki, E.; Edlmann, K.; Haszeldine, R.S. Offshore Geological Storage of Hydrogen: Is This Our Best Option to Achieve Net-Zero? ACS Energy Lett. 2021, 6, 2181-2186. [CrossRef]

52. Hassanpouryouzband, A.; Joonaki, E.; Vasheghani Farahani, M.; Takeya, S.; Ruppel, C.; Yang, J.; English, N.J.; Schicks, J.M.; Edlmann, K.; Mehrabian, H.; et al. Gas hydrates in sustainable chemistry. Chem. Soc. Rev. 2020, 49, 5225-5309. [CrossRef] [PubMed]

53. Hepburn, C.; Adlen, E.; Beddington, J.; Carter, E.A.; Fuss, S.; Mac Dowell, N.; Minx, J.C.; Smith, P.; Williams, C.K. The technological and economic prospects for CO2 utilization and removal. Nature 2019, 575, 87-97. [CrossRef] [PubMed]

54. Zhang, Z.; Pan, S.-Y.; Li, H.; Cai, J.; Olabi, A.G.; Anthony, E.J.; Manovic, V. Recent advances in carbon dioxide utilization. Renew. Sustain. Energy Rev. 2020, 125, 109799. [CrossRef]

55. Ren, S.; Dawson, R.; Laybourn, A.; Jiang, J.-X.; Khimyak, Y.; Adams, D.J.; Cooper, A.I. Functional conjugated microporous polymers: From 1,3,5-benzene to 1,3,5-triazine. Polym. Chem. 2012, 3, 928-934. [CrossRef]

56. Furukawa, H.; Yaghi, O.M. Storage of Hydrogen, Methane, and Carbon Dioxide in Highly Porous Covalent Organic Frameworks for Clean Energy Applications. J. Am. Chem. Soc. 2009, 131, 8875-8883. [CrossRef] 